\title{
Thirty-Four Months Control of Frail Patient with Multisystemic Affection Proved Erdheim Chester Disease: A Case Report
}

\author{
Emad Mohsen Barsoum¹, Fiby Samir Boules ${ }^{1}$, May Gamal Ashour ${ }^{2}$, Mohsen Samy Barsoum¹ \\ ${ }^{1}$ Barsoum Oncology Center (BOC), Cairo, Egypt \\ ${ }^{2}$ Radiation Oncology and Nuclear Medicine Department, National Cancer Institute, Cairo University, Cairo, Egypt \\ Email:emad_barsoum@hotmail.com, fiby.nader@yahoo.com,may.ashour@nci.cu.edu, eg.mbarsoum47@hotmail.com
}

How to cite this paper: Barsoum, E.M., Boules, F.S., Ashour, M.G. and Barsoum, M.S. (2021) Thirty-Four Months Control of Frail Patient with Multisystemic Affection Proved Erdheim Chester Disease: A Case Report. Journal of Cancer Therapy, 12, 689-694.

https://doi.org/10.4236/jct.2021.1212060

Received: November 2, 2021

Accepted: December 10, 2021

Published: December 13, 2021

Copyright $\odot 2021$ by author(s) and Scientific Research Publishing Inc. This work is licensed under the Creative Commons Attribution International License (CC BY 4.0).

http://creativecommons.org/licenses/by/4.0/

\begin{abstract}
Erdheim-Chester disease (ECD) is a rare non-Langerhans form of histiocytosis characterized by multisystemic involvement. We report a case of a 51-year-old male patient treated with pegylated IFN- $\alpha$ in a monthly schedule with low-dose prednisolone and achieved 34 months of control with minimal side effects.
\end{abstract}

\section{Keywords}

Erdheim-Chester Disease, Histiocytoses, Non-Langerhans Cell Histiocytoses

\section{Introduction}

Histiocytoses constitute a heterogeneous group of rare disorders, characterized by infiltration of myeloid cells to almost any organ with diverse macrophage or dendritic cell phenotypes. They are divided into Langerhans cells and non-Langerhans histiocytoses [1].

Non-Langerhans cell histiocytoses include numerous benign or malignant, localized or systemic, adult or pediatric diseases [2].

Some cases have an excellent prognosis after resection, and some even disappear spontaneously, but on the other hand, some progress rapidly and require intensive systemic therapies [2].

\section{Case Presentation}

We report a case of a 51-year-old male patient who presented in March 2018 with two months duration right loin pain radiating to the right lower limb not 
responding to conservative treatment. The patient sought medical advice and underwent several investigations.

Computed tomography (CT) abdomen and pelvis showed lumbar vertebrae three body compression fracture, and wedge collapse suggests neoplastic infiltration, right sacral alum sclerotic marrow infiltration, and large retroperitoneal mass at right hypochondrial region.

PET-CT showed well defined large hepatic focal lesion measuring $15 \times 10.5 \times$ $12.2 \mathrm{~cm}$ with maximum standard uptake value (SUV max) 20.7, multiple small retroperitoneal, para-aortic and retrocaval lymph nodes largest measuring $2 \times 2$ $\mathrm{cm}$, left para-aortic lymph node with SUV max 18.2, collapsed lumber vertebrae three associated with minimal prevertebral soft tissue mass SUV max 15.2, left symphysis pubis lytic lesion SUV max 17.6, right sacral ala sclerotic lesion SUV max 24.2 and right rib lesion SUV max 5.2.

CT-guided biopsy from the sacral and L3 vertebral lesion was done and proved histiocytic disorder like Erdheim-Chester disease, and after immunohistochemistry confirmed Erdheim -Chester disease, CD163 and CD 68 positive.

Serum protein electrophoresis showed polyclonal hypergammaglobulinemia.

The patient received palliative radiotherapy (3000 cGy/10 Fractions) to L3, and the sacrum ended in April 2018.

Then started pegylated interferon-alpha 160 mcg every 28 days with prednisolone $5 \mathrm{mg}$ daily as the patient had poor performance status and couldn't tolerate the recommended weekly dose.

Two months later, in June 2018, the patient had an excellent clinical response in the form of pain improvement and regression of the metabolic activity of the lesions, so he was kept on the same treatment till October 2020, when PET CT showed mild progression in the form of mild increase of the metabolic activity of the old lesions and newly developed bony lesions.

So patient was offered to start chemotherapy adriamycin and vincristine, but he refused, so we advised him to continue pegylated interferon-alpha every 21 days instead of every 28 days.

Three months later, January 2021, PET CT showed stationary morphologic with metabolic regression of activity of large hepatic focal lesion $15 \mathrm{~cm}$ with SUV 15 versus 24.9, abdominal LNs largest left para-aortic $2 \times 2 \mathrm{~cm}$ SUV 16.47 versus 28 , numerous widespread bony lesions the most active at $4^{\text {th }}$ rib SUV 15.9 versus 21 , and left pubic lesion SUV 15.3 versus 21.65 , so the patient was advised to continue same treatment with follow-up PET-CT every six months and BRAF V6000 gene mutation testing for evaluation for further treatment options.

\section{Discussion}

The first case of Erdheim-Chester disease (ECD) was documented in 1930 by Austrian doctor Jakob Erdheim and American pathologist William Chester [3]. Since then, there have been less than 1000 cases reported in the medical literature [4]. 
ECD is a non-Langerhans variant of histiocytosis that often manifests as multisystemic involvement in adults aged 40 - 60, with a male predominance [5].

Clinical signs range from asymptomatic to multisystemic life-threatening forms, including skeletal involvement, exophthalmos, diabetes insipidus, renal impairment, central nervous system, and/or cardiovascular involvement [5].

Prognosis differs according to disease burden and visceral involvement. Patients with visceral infiltration had a poorer prognosis than non-visceral infiltration. Arnaud et al. reported a 1-year survival rate of 96 percent and a 5-year survival rate of 68 percent [6]. Lung fibrosis is the leading cause of mortality, followed by renal failure due to retroperitoneal involvement and heart failure [7].

Treatment varies according to clinical presentation, symptoms, and disease burden. Patients with a low disease burden and asymptomatic may be kept without treatment with watchful waiting. Systemic corticosteroids, surgical excision, and local palliative radiotherapy may be used as symptomatic treatment but not as monotherapy, and other systemic therapy should be offered [8].

Surgical debulking is reserved for significant ocular lesions or intracranial lesions that are surgically resectable in ECD. Corticosteroids may be used immediately to alleviate edema, such as in cases of severe exophthalmos, or used as long-term palliation for patients who can't tolerate treatment side effects [8].

Malignant non-Langerhans cell histiocytoses have a poor prognosis in general, necessitating sophisticated treatment procedures with inconsistent outcomes. Before the discovery of IFN- $\alpha$, several treatment regimens utilizing cytotoxic chemotherapies were described in small series, including vinca alkaloids, anthracyclines, methotrexate, and cyclophosphamide high-dose chemotherapy in combination with autologous stem cell transplantation [9] [10] [11].

PEG-IFN- $\alpha 135 \mu \mathrm{g} \mathrm{SC/wk}$ (standard dose) or $180 \mu \mathrm{g} \mathrm{SC/wk}$ (high dose) is ECD's gold standard of treatment as the first-line therapy with the most substantial clinical evidence. Case reports have shown a survival advantage for individuals with CNS or cardiac involvement when treated with any kind of IFN- $\alpha$, particularly high-dose IFN- $\alpha$ [12] [13] [14] [15].

It was interesting to have a biomarker to target to improve results. Around $50 \%$ of patients with specific subtypes of non-Langerhans cell histiocytoses have BRAF mutations [2].

In November 2017, The FDA approved vemurafenib to treat selected adult patients with ECD who had the BRAF V6000 gene mutation [16].

Cobimetinib, a MEK inhibitor, has been utilized more recently in patients with BRAF wild-type cancer or who cannot tolerate or respond to Vemurafenib [17].

Other therapies include Tocilizumab, an anti-IL6 antibody now undergoing clinical trials in ECD patients based on systemic IL-6 elevations observed in ECD patients [18].

Sirolimus and prednisone were evaluated to disrupt immunological dysregulation in ECD. Additionally, the recent finding of an activating RAS mutation in ECD may give a reason for sirolimus suppression of mTOR in certain patients 
[19].

Cladribine $6 \mathrm{mg} / \mathrm{m}^{2}$ IV daily for five days every four weeks is a second-line therapeutic option. It has been used in clinical studies, although few published reports of its effectiveness [20] [21].

Imatinib $400 \mathrm{mg}$ PO daily, even though no known mutations in KIT, ABL, or PDGFR are associated with histiocytic diseases. Specific histiocytic lesions in ECD and similar illnesses appear to display a high level of PDGFR- $\beta$. Imatinib treatment results in seven ECD individuals have been inconsistent, although it seems to be more beneficial in milder types of the condition [22] [23].

Infliximab $5 \mathrm{mg} / \mathrm{mg}$ IV every six weeks improved clinical outcomes in four individuals with refractory heart illness to IFN- $\alpha$ therapy [24].

\section{Conclusions}

ECD is a rare disease with emerging data about therapy. The only approved data about treatment is IFN- $\alpha$ weekly and anti BRAF for cases with BRAF V6000 gene mutation.

Unfortunately, all these treatment options have a lot of side effects and may not be suitable for frail patients with comorbidities.

The only accepted treatment for the frail patient was palliative radiotherapy and steroids. We used pegylated IFN- $\alpha$ with a monthly schedule with low-dose prednisolone to control this frail patient who didn't tolerate the approved weekly treatment as a palliative modality and achieved 34 months of control with minimal side effects.

We recommend tailoring treatment for patients with ECD to get adequate tumor control with minimal adverse events.

\section{Conflicts of Interest}

The authors declare no conflicts of interest regarding the publication of this paper.

\section{References}

[1] Emile, J.F., Cohen-Aubart, F., Collin, M., Fraitag, S., Idbaih, A., Abdel-Wahab, O., Rollins, B.J., Donadieu, J. and Haroche, J. (2021) Histiocytosis. The Lancet, 398, 157-170. https://doi.org/10.1016/S0140-6736(21)00311-1

[2] Classen, C.F., Minkov, M. and Lehrnbecher, T. (2016) The Non-Langerhans Cell Histiocytoses (Rare Histiocytoses)_Clinical Aspects and Therapeutic Approaches. Klinische Pädiatrie, 228, 294-306. https://doi.org/10.1055/s-0042-109713

[3] Singh, P., Shrestha, R. and Yadav, N.K. (2020) Erdheim Chester Disease: A Subtle Quiddity; the First Case Reported from Nepal. Radiology Case Reports, 15, 2080-2084. https://doi.org/10.1016/j.radcr.2020.08.014

[4] Cives, M., Simone, V., Rizzo, F.M., Dicuonzo, F., Cristallo Lacalamita, M., Ingravallo, G., Silvestris, F. and Dammacco, F. (2015) Erdheim-Chester Disease: A Systematic Review. Critical Reviews in Oncology/ Hematology, 95, 1-11. https://doi.org/10.1016/j.critrevonc.2015.02.004

[5] Mazor, R.D., Manevich-Mazor, M. and Shoenfeld, Y. (2013) Erdheim-Chester Dis- 
ease: A Comprehensive Review of the Literature. Orphanet Journal of Rare Diseases, 8, Article No. 137. https://doi.org/10.1186/1750-1172-8-137

[6] Arnaud, L., Hervier, B., Néel, A., Hamidou, M.A., Kahn, J.E., Wechsler, B., Pérez-Pastor, G., Blomberg, B., Fuzibet, J.G., Dubourguet, F., Marinho, A., Magnette, C., Noel, V., Pavic, M., Casper, J., Beucher, A.B., Costedoat-Chalumeau, N., Aaron, L., Salvatierra, J., Graux, C., Cacoub, P., Delcey, V., Dechant, C., Bindi, P., Herbaut, C., Graziani, G., Amoura, Z. and Haroche, J. (2011) CNS Involvement and Treatment with Interferon- $\alpha$ Are Independent Prognostic Factors in Erdheim-Chester disease: A Multicenter Survival Analysis of 53 Patients. Blood, 117, 2778-2782. https://doi.org/10.1182/blood-2010-06-294108

[7] Matzumura, M., Arias-Stella, J. and Novak, J.E. (2016) Erdheim-Chester Disease: A Rare Presentation of a Rare Disease. Journal of Investigative Medicine High Impact Case Reports, 4, 1-4. https://doi.org/10.1177/2324709616663233

[8] Diamond, E.L., Dagna, L., Hyman, D.M., Cavalli, G., Janku, F., Estrada-Veras, J., Ferrarini, M., Abdel-Wahab, O., Heaney, M.L., Scheel, P.J., Feeley, N.K., Ferrero, E., McClain, K.L., Vaglio, A., Colby, T., Arnaud, L. and Haroche, J. (2014) Consensus Guidelines for the Diagnosis and Clinical Management of Erdheim-Chester Disease. Blood, 124, 483-492. https://doi.org/10.1182/blood-2014-03-561381

[9] Jendro, M.C., Zeidler, H., Rosenthal, H., Haller, H. and Schwarz, A. (2004) Improvement of Erdheim-Chester Disease in Two Patients by Sequential Treatment with Vinblastine and Mycophenolate Mofetil. Clinical Rheumatology, 23, 52-56. https://doi.org/10.1007/s10067-003-0801-7

[10] Yano, S., Kobayashi, K., Kato, K., Tokuda, Y., Ikeda, T. and Takeyama, H. (2007) A Case of Erdheim-Chester Disease Effectively Treated by Cyclophosphamide and Prednisolone. Nihon Kokyuki Gakkai Zasshi, 45, 43-48.

[11] Gaspar, N., Boudou, P., Haroche, J., Wechsler, B., Van Den Neste, E., Hoang-Xuan K, Amoura, Z., Guillevin, R., Savatovski, J., Azar, N., Piette, J.C. and Leblond, V. (2006) High-Dose Chemotherapy Followed by Autologous Hematopoietic Stem Cell Transplantation for Adult Histiocytic Disorders with Central Nervous System Involvement. Haematologica, 91, 1121-1125.

[12] Esmaeli, B., Ahmadi, A., Tang, R., Schiffman, J. and Kurzrock, R. (2001) Interferon Therapy for Orbital Infiltration Secondary to Erdheim-Chester Disease. American Journal of Ophthalmology, 132, 945-947. https://doi.org/10.1016/S0002-9394(01)01141-2

[13] Suzuki, H.I., Hosoya, N., Miyagawa, K., Ota, S., Nakashima, H., Makita, N. and Kurokawa, M. (2010) Erdheim-Chester Disease: Multisystem Involvement and Management with Interferon- $\alpha$. Leukemia Research, 34, e21-e24.

https://doi.org/10.1016/j.leukres.2009.07.026

[14] Haroche, J., Amoura, Z., Trad, S.G., Wechsler, B., Cluzel, P., Grenier, P.A. and Piette, J.C. (2006) Variability in the Efficacy of Interferon- $\alpha$ in Erdheim-Chester Disease by Patient and Site of Involvement: Results in Eight Patients. Arthritis \& Rheumatology, 54, 3330-3336. https://doi.org/10.1002/art.22165

[15] Hervier, B., Arnaud, L., Charlotte, F., Wechsler, B., Piette, J.C., Amoura, Z. and Haroche, J. (2012) Treatment of Erdheim-Chester Disease with Long-Term High-Dose Interferon- $\alpha$. Seminars in Arthritis and Rheumatism, 41, 907-913.

https://doi.org/10.1016/j.semarthrit.2011.11.004

[16] Oneal, P.A., Kwitkowski, V., Luo, L., Shen, Y.L., Subramaniam, S., Shord, S., Goldberg, K.B., McKee, A.E., Kaminskas, E., Farrell, A. and Pazdur, R. (2018) FDA Approval Summary: Vemurafenib for the Treatment of Patients with Erdheim-Chester 
Disease with the BRAFV600 Mutation. The Oncologist, 23, 1520-1524. https://doi.org/10.1634/theoncologist.2018-0295

[17] Cohen Aubart, F., Emile, J.F., Maksud, P., Galanaud, D., Cluzel, P., Benameur, N. Aumaitre, O., Amoura, Z. and Haroche, J. (2018) Efficacy of the MEK Inhibitor Cobimetinib for Wild-Type BRAF Erdheim-Chester Disease. British Journal of Haematology, 180, 150-153. https://doi.org/10.1111/bjh.14284

[18] Arnaud, L., Gorochov, G., Charlotte, F., Lvovschi, V., Parizot, C., Larsen, M., Ghillani-Dalbin, P., Hervier, B., Kahn, J.E., Deback, C., Musset, L., Amoura, Z. and Haroche, J. (2011) Systemic Perturbation of Cytokine and Chemokine Networks in Erdheim-Chester Disease: A Single-Center Series of 37 Patients. Blood, 117, 2783-2790. https://doi.org/10.1182/blood-2010-10-313510

[19] Diamond, E.L., Abdel-Wahab, O., Pentsova, E., Borsu, L., Chiu, A., Teruya-Feldstein, J., Hyman, D.M. and Rosenblum, M. (2013) Detection of an NRAS Mutation in Erdheim-Chester Disease. Blood, 122, 1089-1091. https://doi.org/10.1182/blood-2013-02-482984

[20] Girschikofsky, M., Arico, M., Castillo, D., Chu, A., Doberauer, C., Fichter, J., Haroche, J., Kaltsas, G.A., Makras, P., Marzano, A.V., de Menthon, M., Micke, O., Passoni, E., Seegenschmiedt, H.M., Tazi, A. and McClain, K.L. (2013) Management of Adult Patients with Langerhans Cell Histiocytosis: Recommendations from an Expert Panel on Behalf of Euro-Histio-Net. Orphanet Journal of Rare Diseases, 8, Article No. 72. https://doi.org/10.1186/1750-1172-8-72

[21] Myra, C., Sloper, L., Tighe, P.J., McIntosh, R.S., Stevens, S.E., Gregson, R.H., Sokal, M., Haynes, A.P. and Powell, R.J. (2004) Treatment of Erdheim-Chester Disease with Cladribine: A Rational Approach. British Journal of Ophthalmology, 88, 844-847. https://doi.org/10.1136/bjo.2003.035584

[22] Haroche, J., Amoura, Z., Charlotte, F., Salvatierra, J., Wechsler, B., Graux, C., Brousse, N. and Piette, J.C. (2008) Imatinib Mesylate for Platelet-Derived Growth Factor Receptor-Beta-Positive Erdheim-Chester Histiocytosis. Blood, 111, 5413-5415. https://doi.org/10.1182/blood-2008-03-148304

[23] Janku, F., Amin, H.M., Yang, D., Garrido-Laguna, I., Trent, J.C. and Kurzrock, R. (2010) Response of Histiocytoses to Imatinib Mesylate: Fire to Ashes. Journal of Clinical Oncology, 28, e633-e636. https://doi.org/10.1200/JCO.2010.29.9073

[24] Dagna, L., Corti, A., Langheim S., Guglielmi, B., De Cobelli, F., Doglioni, C., Fragasso, G., Sabbadini, M.G. and Ferrarini, M. (2012) Tumor Necrosis Factor $\alpha$ as a Master Regulator of Inflammation in Erdheim-Chester Disease: Rationale for the Treatment of Patients with Infliximab. Journal of Clinical Oncology, 30, e286-e290. https://doi.org/10.1200/JCO.2012.41.9911 